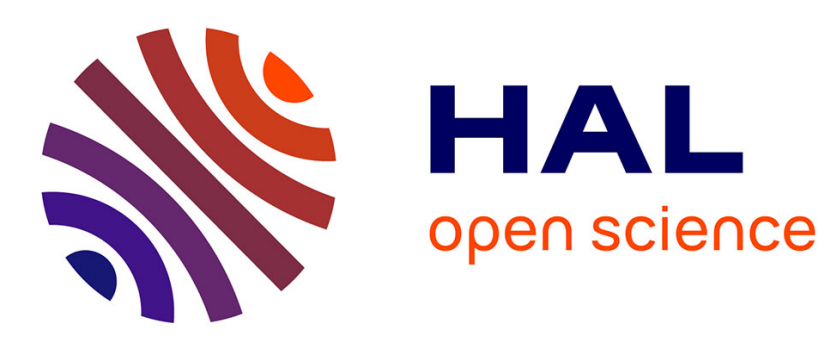

\title{
Investigation of the neutron-deficient isotope 123Ba
}

N. Yoshikawa, J. Gizon, A. Gizon

\section{To cite this version:}

N. Yoshikawa, J. Gizon, A. Gizon. Investigation of the neutron-deficient isotope 123Ba. Journal de Physique, 1979, 40 (3), pp.209-213. 10.1051/jphys:01979004003020900 . jpa-00208900

\section{HAL Id: jpa-00208900 https://hal.science/jpa-00208900}

Submitted on 1 Jan 1979

HAL is a multi-disciplinary open access archive for the deposit and dissemination of scientific research documents, whether they are published or not. The documents may come from teaching and research institutions in France or abroad, or from public or private research centers.
L'archive ouverte pluridisciplinaire $\mathbf{H A L}$, est destinée au dépôt et à la diffusion de documents scientifiques de niveau recherche, publiés ou non, émanant des établissements d'enseignement et de recherche français ou étrangers, des laboratoires publics ou privés. 


\title{
LE JOURNAL DE PHYSIQUE
}

Classification

Physics Abstracts

$21.60-27.60$

\section{Investigation of the neutron-deficient isotope ${ }^{123} \mathrm{Ba}$}

\author{
N. Yoshikawa (*), J. Gizon and A. Gizon \\ Institut des Sciences Nucléaires (USMG, IN2 P3), 53, avenue des Martyrs, 38026 Grenoble Cedex, France
}

(Reçu le 16 octobre 1978, accepté le 22 novembre 1978)

\begin{abstract}
Résumé. - Des niveaux de haut-spin dans ${ }^{123} \mathrm{Ba}$ ont été produits dans la réaction ${ }^{1{ }^{14}} \mathrm{Sn}\left({ }^{12} \mathrm{C}, 3 \mathrm{n}\right)$ et étudiés selon les techniques de spectroscopie $\gamma$ en ligne. La structure en bande fortement peuplée qui a été identifiée repose sur un état $7 / 2^{-}$et peut s'expliquer par le couplage d'un trou de neutron $\mathrm{h}_{11 / 2}$ au cœur triaxial de type prolate. Elle est comparée à celle existant dans des isotopes plus lourds de Ba et des isotones $N=67$.
\end{abstract}

\begin{abstract}
High-spin levels in ${ }^{123} \mathrm{Ba}$ have been produced in the ${ }^{114} \operatorname{Sn}\left({ }^{12} \mathrm{C}, 3 \mathrm{n}\right)$ reaction and studied by in-beam $\gamma$-ray spectroscopic techniques. Only one strongly populated band structure has been identified and explained as an odd-parity level system based on a $7 / 2^{-}$state generated by the coupling of an $\mathrm{h}_{11 / 2}$ neutron-hole to a prolate-type triaxial core. Comparisons with heavier odd $A$ Ba isotopes and $N=67$ isotones are made.
\end{abstract}

1. Introduction. - In the last few years, systematic studies of excited states in nuclei of the transitional regions have revealed a wide variety of new information. Though the nuclear structure in the $A \approx 190$ region seems now to be relatively well understood, especially through studies of $\mathrm{Ir}, \mathrm{Pt}, \mathrm{Au}, \mathrm{Hg}$ and $\mathrm{Tl}$ isotopes, it is necessary to extend the effort towards other transitional regions where the experimental data are still scarce.

Several studies of high-spin states excited by (HI, $x \mathrm{n})$ reactions in odd- $A{ }^{125,133} \mathrm{Ba}$ [1], ${ }^{129-135} \mathrm{Ce}$ [2] and ${ }^{133-139} \mathrm{Nd}[3]$ isotopes have pointed out the existence of typical band structure patterns based upon neutronhole configurations $\left(\mathrm{h}_{11 / 2}, \mathrm{~g}_{7 / 2}\right)$. Though several theoretical approaches can reproduce such structures, until now we have interpreted our results only within the frame of the triaxial rotor-plus-particle model developed by $\mathbf{J}$. Meyer-ter-Vehn [4]. This model is especially able to explain the level subsystems and the two-dimensional patterns observed experimentally in the negative parity levels associated with an $h_{11 / 2}$ neutron-hole [5].

To learn more about nuclei of this region and eventually to test the applicability of different models when the Fermi surface penetrates inside a given shell, it is necessary to obtain more experimental details towards more deficient nuclei.

Though the production of very neutron-deficient isotopes from heavy-ion compound nuclei is limit-

${ }^{*}$ ) On leave from the Institute for Nuclear Study, Tokyo, Japan. ed [6], we have undertaken the study of ${ }^{123} \mathrm{Ba}$ with the ${ }^{114} \mathrm{Sn}+{ }^{12} \mathrm{C}$ reaction to search for its high-spin excited states.

To date, the ground-state spin of ${ }^{123} \mathrm{Ba}$ is unknown. Arlt et al. [7] have identified seven low-energy $\gamma$-rays of $(2.7 \pm 0.4) \mathrm{min}$. half-life associated with the decay of ${ }^{123} \mathrm{Ba}$ produced in the ${ }^{114} \mathrm{Sn}\left({ }^{12} \mathrm{C}, 3 \mathrm{n}\right){ }^{123} \mathrm{Ba}$ reaction. Using in-beam spectroscopic methods, Conrad and Repnow [8] have assigned to ${ }^{123} \mathrm{Ba}$, a cascade of stretched E2 transitions of 321, 522.5, 684.5 and $799 \mathrm{keV}$ from the ${ }^{110} \mathrm{Cd}\left({ }^{16} \mathrm{O}, 3 \mathrm{n}\right)$ reaction. Unfortunately, the particle- $\gamma$ coincidence measurements that we have performed [9] and two other very recent experiments [10], [11] prove that this assignment is wrong and until now, ${ }^{123} \mathrm{Ba}$ is quite unknown.

2. Experimental techniques. - Targets. of rolled metallic tin enriched to $66.5 \%$ in ${ }^{114} \mathrm{Sn}$ and backed with $25 \mu \mathrm{m}$ of lead were bombarded at the Grenoble variable energy cyclotron with ${ }^{12} \mathrm{C}$ ions in the energy range from $52 \mathrm{MeV}$ to $63 \mathrm{MeV}$. The maximum cross section for three particles emission was found at $57 \mathrm{MeV}$.

In-beam and out-of-beam $\gamma$-ray singles spectra have been obtained with several $\mathrm{Ge}(\mathrm{Li})$ detectors, in particular with a $3.5 \mathrm{~cm}^{3}$ planar having a resolution of $0.7 \mathrm{keV} \mathrm{FWHM}$ at $122 \mathrm{keV}$ and with a $30 \mathrm{~cm}^{3}$ coaxial having a resolution of $2.0 \mathrm{keV}$ FWHM at $1.3 \mathrm{MeV}$. The energies of $\gamma$-lines were determined by recording simultaneously the $\gamma$-rays emitted by the target and standard calibration sources. Several measurements 
have been done after irradiation of the target to look for short-lived and long-lived activity spectra. The angular distributions of the $\gamma$-rays were made at six different angles including $0^{\circ}$ relative to the beam direction. The $\gamma-\gamma-t$ coincidence measurements were performed with two $30 \mathrm{~cm}^{3}$ coaxial $\mathrm{Ge}(\mathrm{Li})$ detectors. Moreover, to separate the $\left({ }^{12} \mathrm{C}, 3 \mathrm{n}\right)$ reaction from the $\left({ }^{12} \mathrm{C}, \mathrm{p} 2 \mathrm{n}\right),\left({ }^{12} \mathrm{C}, 2 \mathrm{pn}\right)$ and $\left({ }^{12} \mathrm{C}, \alpha 2 \mathrm{n}\right)$ reactions, we have carried out $\gamma$-particles coincidence measurements. In this experiment, protons and $\alpha$-particles were detected with a silicon detector covered by a $400 \mu \mathrm{g} / \mathrm{cm}^{2}$ absorber and placed near the target.

3. Experimental results and assignments. - Since nothing was known about the ground and excited states of ${ }^{123} \mathrm{Ba}$, the first difficult task was to identify the transitions belonging to this isotope. For this purpose we have carefully analysed all experimental data as in-beam and out-of-beam singles spectra, excitation functions and particle- $\gamma$ coincidences spectra. Series of singles spectra recorded successively after bombardments of the target were also a valuable tool to identify the $\gamma$-rays associated with the decay of the $A=123$ chain [7], [12], [13]. The low energy part of a singles $\gamma$-spectrum recorded with a planar detector is shown in figure 1 , as an example. The
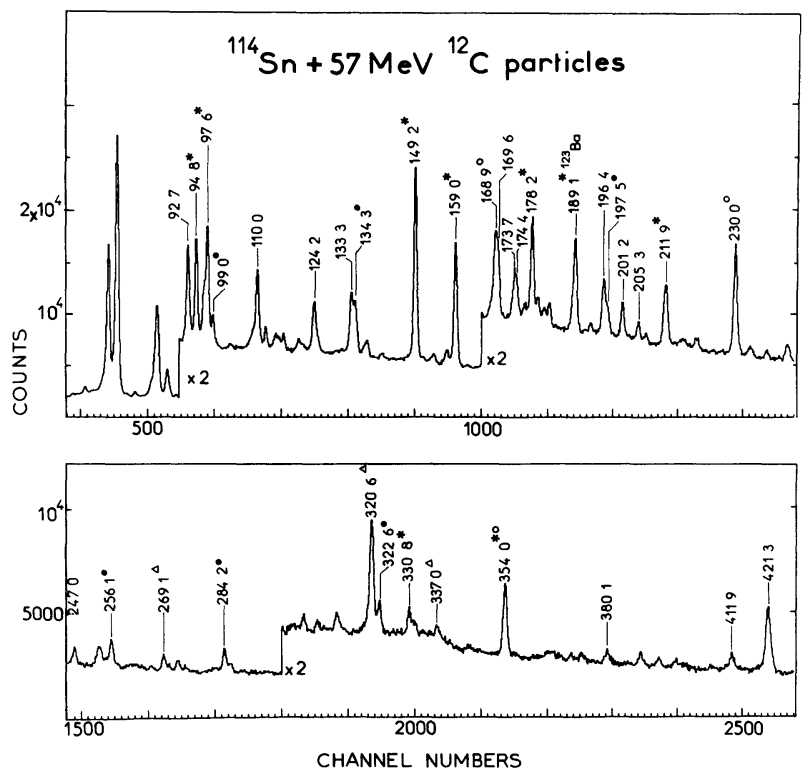

Fig. 1. - In-beam $\gamma$-ray spectrum observed with a planar detector at $90^{\circ}$ to the beam in the ${ }^{114} \mathrm{Sn}+{ }^{12} \mathrm{C}$ reaction at $57 \mathrm{MeV}$. The asterisks (open circles) indicate $\gamma$-lines in the $A=123$ (124) decay chains. The full circles correspond to $\gamma$-rays associated with target impurities and the triangles to $\gamma$-rays in ${ }^{123} \mathrm{Cs}$.

second step of the identification is mainly based on the $\gamma-\gamma$ coincidences. With all these approaches, the excitation of several isotopes has been well identified, especially those previously studied by in-beam spectroscopy. It is the case of ${ }^{120} \mathrm{Xe}$ excited here by $\left({ }^{12} \mathrm{C}, \alpha 2 \mathrm{n}\right)$ reaction and known from the

$$
{ }^{109} \mathrm{Ag}\left({ }^{14} \mathrm{~N}, 3 \mathrm{n}\right) \text { and }{ }^{111} \mathrm{Cd}\left({ }^{12} \mathrm{C}, 3 \mathrm{n}\right)
$$

reactions [14]. The ${ }^{114} \mathrm{Sn}\left({ }^{12} \mathrm{C}, \mathrm{p} 2 \mathrm{n}\right){ }^{123} \mathrm{Cs}$ channel is strongly fed at $57 \mathrm{MeV}$ and produces the more intense lines in the particle- $\gamma$ coincidences spectrum. The corresponding partial level scheme of ${ }^{123} \mathrm{Cs}$, established in this experiment, has been already published with results concerning ${ }^{125} \mathrm{Cs}$ and ${ }^{121} \mathrm{Cs}$ [9].

It was easy to eliminate the isotopes produced by $\left({ }^{12} \mathrm{C}, 3 \mathrm{n}\right)$ reactions on the impurities of ${ }^{116,118} \mathrm{Sn}$ present in the target because they have been previously studied in our group by in-beam spectroscopy [1].

Information on the transitions placed in the partial level scheme proposed for ${ }^{123} \mathrm{Ba}$ is reported in table I. The energies of the $\gamma$-rays are given with a precision better than $0.1 \%$ for the strong and resolved lines. The results of the coincidence measurements are summarized in table II.

Table I. - Transitions of ${ }^{123} \mathrm{Ba}$ observed in the ${ }^{114} \mathrm{Sn}\left({ }^{12} \mathrm{C}, 3 \mathrm{n}\right)$ reaction at $57 \mathrm{MeV}$

\begin{tabular}{|c|c|c|c|}
\hline $\begin{array}{c}E_{\gamma} \\
\mathrm{keV}\end{array}$ & $\begin{array}{c}I_{\gamma}\left(125^{\circ}\right) \\
\text { relative }\end{array}$ & $A_{2} / A_{0}$ & Transition \\
\hline - & - & & - \\
\hline 92.7 & $102(8)$ & $-0.20(5)$ & $7 / 2^{-} \rightarrow\left(5 / 2^{+}\right)$ \\
\hline 110.0 & $100(8)\left({ }^{a}\right)$ & $-0.41(7)$ & $9 / 2^{-} \rightarrow 7 / 2^{-}$ \\
\hline $\left.133.3^{(b}\right)$ & $\sim 81\left(^{\circ}\right)$ & $-0.45(10)$ & $11 / 2^{-} \rightarrow 9 / 2^{-}$ \\
\hline $169.6\left(^{b}\right)$ & $\sim 30$ & & $\left(7 / 2^{+}\right) \rightarrow ?$ \\
\hline $174.4\left(^{b}\right)$ & $\sim 23\left(^{(}\right)$ & & $15 / 2^{-} \rightarrow 13 / 2^{-}$ \\
\hline $189.1\left(^{b}\right)$ & $\sim 33\left({ }^{c}\right)$ & & $19 / 2^{-} \rightarrow 17 / 2^{-}$ \\
\hline 205.3 & $28(4)$ & $-0.54(16)$ & $\left(9 / 2^{+}\right) \rightarrow\left(7 / 2^{+}\right)$ \\
\hline 238.1 & $14(3)$ & $-0.31(9)$ & $\left(11 / 2^{+}\right) \rightarrow\left(9 / 2^{+}\right)$ \\
\hline 247.0 & $30(4)$ & $-0.73(8)$ & $13 / 2^{-} \rightarrow 11 / 2^{-}$ \\
\hline $380.1\left(^{b}\right)$ & $37(7)$ & $+0.04(10)$ & $\begin{cases}13 / 2^{-} & \rightarrow 9 / 2^{-} \\
17 / 2^{-} & \rightarrow 15 / 2^{-}\end{cases}$ \\
\hline $421.3\left(^{b}\right)$ & $\sim 118$ & $+0.29(6)$ & $15 / 2^{-} \rightarrow 11 / 2^{-}$ \\
\hline 553.7 & $30(5)$ & $+0.21(7)$ & $17 / 2^{-} \rightarrow 13 / 2^{-}$ \\
\hline 569.0 & $72(11)$ & $+0.20(6)$ & $19 / 2^{-} \rightarrow 15 / 2^{-}$ \\
\hline $694.7\left(^{b}\right)$ & $\sim 55$ & $+0.28(2)$ & $23 / 2^{-} \rightarrow 19 / 2^{-}$ \\
\hline $780.6^{(b)}$ & $\sim 34$ & & $\left(27 / 2^{-}\right) \rightarrow 23 / 2^{-}$ \\
\hline
\end{tabular}

$\left({ }^{a}\right)$ Relative intensities normalized to this line.

(b) Composite line.

$\left({ }^{c}\right)$ Value deduced from the $\gamma-\gamma$ coincidence spectra.

The partial level scheme proposed in figure 2 was constructed on the basis of experimental data and keeping in mind the systematic results known for oddmass heavier $\mathrm{Ba}$ isotopes.

From delayed $\gamma$-ray spectra recorded between the beam bursts of the cyclotron, a delayed component with a $T_{1 / 2}=40 \mathrm{~ns}$ half-life has been found in the very strong $92.7 \mathrm{keV}$ transition of the singles spectrum, the other one being identified with

$$
{ }^{123} \mathrm{Ba} \rightarrow{ }^{123} \mathrm{Cs} \quad \text { [7] . }
$$

This delayed $92.7 \mathrm{keV}$ line is in coincidence with a cascade made of most of the strong transitions assigned to ${ }^{123} \mathrm{Ba}$, in particular with the $110.0,133.3,421.3$, $569.0,694.7$ and $780.6 \mathrm{keV}$ prompt $\gamma$-rays. In this cascade, the 110.0 and $133.3 \mathrm{keV} \gamma$-rays have sharp negative $A_{22}$ coefficients characteristic of $\mathrm{M} 1+\mathrm{E} 2$ $(I+1 \rightarrow I)$ transitions while the other members (the 
Table II. - Gamma rays observed in coincidence with lines of ${ }^{123} \mathrm{Ba}$ in the reaction $\left({ }^{114} \mathrm{Sn}+{ }^{12} \mathrm{C}\right)$

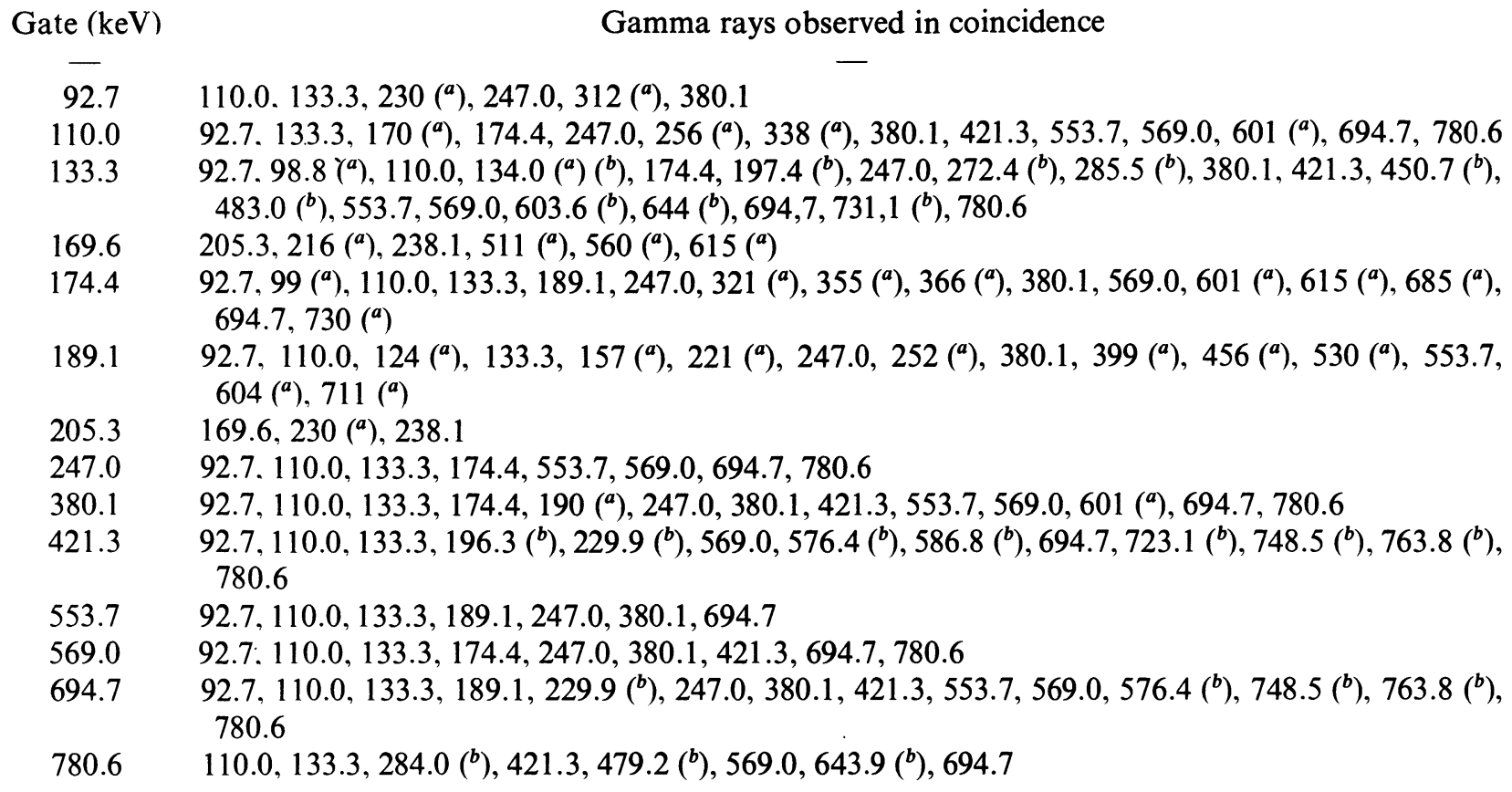

( $\left.{ }^{a}\right)$ Transition not placed in the level scheme.

$\left({ }^{b}\right)$ Transition belonging to neighbouring isotopes as ${ }^{124,125,127,128} \mathrm{Ba}$ and ${ }^{121} \mathrm{Xe}$.

(a)

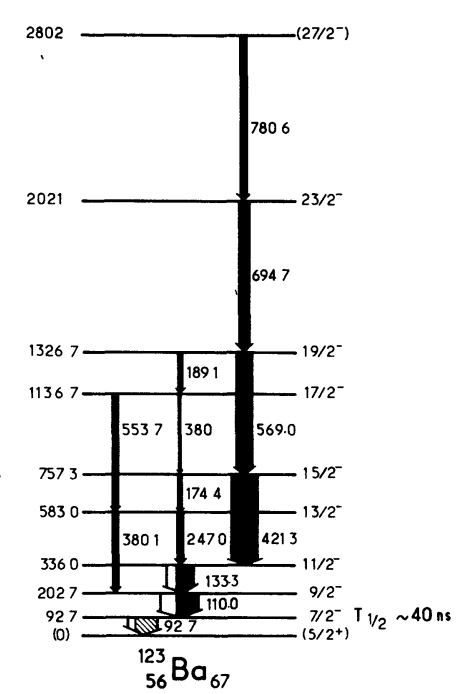

(b)

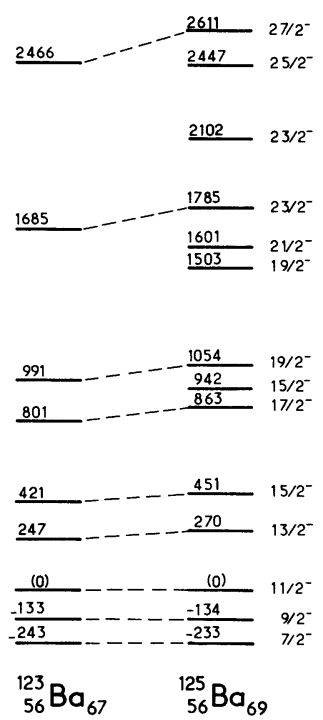

Fig. 2. - Part (a) is the partial level scheme of ${ }^{123} \mathrm{Ba}$ obtained in the ${ }^{114} \mathrm{Sn}\left({ }^{12} \mathrm{C}, 3 \mathrm{n}\right)$ reaction. The black and white components of the arrows represent the $\gamma$-intensity and the estimated internal conversion contribution, respectively. A comparison of the $h_{11 / 2}$ band structure in both ${ }^{125} \mathrm{Ba}$ and ${ }^{123} \mathrm{Ba}$ is made in part $(b)$ where the energies are normalized such that the $11 / 2^{-}$states are all set to zero.

421-569-695-781 keV lines) present positive $A_{22}^{\exp }$ coefficients characteristic of pure E2 $(I+2 \rightarrow I)$ transitions.

By comparison with heavier barium isotopes, this group of transitions belong to the Yrast cascade preferentially populated by the deexcitation of the compound nucleus formed in the reaction and is assigned as a part of the odd-parity system generated from the $h_{11 / 2}$ neutron shell. The resemblance of this cascade to that already identified in ${ }^{125} \mathrm{Ba}$ is striking and constitutes the basis of our spin assignments in ${ }^{123} \mathrm{Ba}$. As in other odd-mass barium isotopes excited by $(\mathrm{HI}, x \mathrm{n})$ reactions, the sequence of stretched E2 transitions comes to the $11 / 2^{-}$state. In the present case, as in ${ }^{125} \mathrm{Ba}$, this $11 / 2^{-}$level is successively depopulated to the $9 / 2^{-}$state by the $133.3 \mathrm{keV}, \mathrm{M} 1+\mathrm{E} 2$ transition and to the $7 / 2^{-}$basic state of the system, by the $110.0 \mathrm{keV}, \mathrm{M} 1+\mathrm{E} 2$ transitions. Looking at the $\gamma-\gamma$ coincidence spectra, few other weak transitions have been placed in this negative parity system. However, it was impossible to establish the existence of a second $15 / 2^{-}$state or to display a two-dimensional level pattern as observed in heavier odd-mass $\mathrm{Ba}$ and $\mathrm{Ce}$ isotopes.

It is more difficult now to connect this odd-parity system based upon a $7 / 2^{-}$state to lower unknown states of ${ }^{123} \mathrm{Ba}$. From prompt and delayed $\gamma-\gamma$ coincidences spectra and $\gamma$-rays intensities it is established that the delayed $92.7 \mathrm{keV}$ line depopulates the $7 / 2^{-}$ level.

This $92.7 \mathrm{keV}$ transition has a $L=1$-type multipolarity deduced from the angular distribution measurements. The E1 electric dipole character seems to be the most probable from lifetime considerations and the corresponding hindrance factor would be of the 
order of $10^{5}$. In case of such an E1 multipolarity, the $92.7 \mathrm{keV} \gamma$-ray feeds a state whose spin and parity are very likely $5 / 2^{+}$. Indeed, the $I^{\pi}=7 / 2^{+}$assignment is excluded by the negative $A_{22}$ angular distribution coefficient and $I^{\pi}=9 / 2^{+}$corresponds to an almost fully aligned $7 / 2^{+}$state. This last possibility $9 / 2^{+}$must also be eliminated because there is no such intrinsic $9 / 2^{+}$state for $N=67$ at moderate $\beta$ deformations.

A $\mathrm{g}_{7 / 2}$ band has been identified [15] in several oddmass $\mathrm{Ba}$ and $\mathrm{Ce}$ isotopes with $N \leqslant 73$. Though its excitation is smaller in ${ }^{125} \mathrm{Ba}$ than in ${ }^{127,129} \mathrm{Ba}$, one can hope nevertheless to observe it in ${ }^{123} \mathrm{Ba}$. For this purpose, the $\gamma-\gamma$ coincidences spectra gated with $\gamma$-rays following a three neutron emission in the $\left({ }^{114} \mathrm{Sn}+{ }^{12} \mathrm{C}\right)$ reaction have been carefully analysed. Only one sequence made of three weak lines at 169.6, 205.3 and $238.1 \mathrm{keV}$ with respective intensities of 30,28 and 14 in scale used in table $I$ has been retained. Both the 205 and $238 \mathrm{keV}$ transitions have a sizeable negative anisotropy in the angular distribution measurements but, unfortunately, it is impossible to determine the anisotropy of the $169.6 \mathrm{keV}$ line which is composite, one part being in the ${ }^{124} \mathrm{Ba} \rightarrow{ }^{124} \mathrm{Cs}$ $\left(T_{1 / 2}=11.9\right.$ min. $)$ [16].

It appears that the $\mathrm{g}_{7 / 2}$ neutron-hole structure does not change very much when one goes from ${ }^{127} \mathrm{Ba}$ to ${ }^{125} \mathrm{Ba}[15]$. This is related to the small change of the Fermi energy when two neutrons are removed from the nucleus. This stability in the $g_{7 / 2}$ level structure could very likely continue towards more neutrondeficient isotopes, in particular for ${ }^{123} \mathrm{Ba}$, because of the large number of positive-parity orbitals $\left(s_{1 / 2}\right.$, $\mathrm{g}_{7 / 2}$ and $\mathrm{d}_{5 / 2}$ ) which exist in this region. $A \quad \Delta I=1$ cascade formed with the $216,255,291,323 \ldots \mathrm{keV}$, $\mathrm{M} 1+\mathrm{E} 2$ transitions has been identified in the $\mathrm{g}_{7 / 2}$ band of ${ }^{125} \mathrm{Ba}$ and the $7 / 2^{+}$basic state of this band is de-excited by a strong $168.6 \mathrm{keV} \gamma$-ray which probably has an M1 multipolarity [17]. This suggests that the 205 and $238 \mathrm{keV}, \mathrm{M} 1+\mathrm{E} 2$ lines of ${ }^{123} \mathrm{Ba}$ could be the two first transitions of this $g_{7 / 2}$ band and that the $169.6 \mathrm{keV}$ could depopulate the $7 / 2^{+}$base level towards a lower state. As mentioned above concerning the density of neutron orbitals in this region, this state probably has a positive parity.

4. Discussion. - 4.1 Comparison of ${ }^{123} \mathrm{Ba}$ WITH Ba ISOTOPES. - The $\Delta I=1$ odd-parity band in ${ }^{123} \mathrm{Ba}$ is similar to those observed in heavier Ba nuclei [17] and its existence in a wide range of masses is in favor of a collective structure.

The bands found in transitional nuclei can be interpreted by several theoretical models but, in the $50<Z, N<82$ region, most of full calculations of energies, transition probabilities, moments, half-lives have been made within the frame of the triaxial-rotorplus-particle model [4]. The $\Delta I=1$ band structure in the odd- $A{ }^{125-133} \mathrm{Ba}$ nuclei is explained as resulting from the coupling of an $\mathrm{h}_{11 / 2}$ neutron-hole to a $\beta$ and $\gamma$ deformed core. Though this $\Delta I=1$ band in ${ }^{123} \mathrm{Ba}$ is not specially well developed i.e. the number of known levels is not very large, it appears reasonable to treat it in the triaxial-core model. This is justified by considering the properties of this band in the ${ }^{123-133} \mathrm{Ba}$ systematics. Indeed level energies and branching ratios vary in a monotonous way when going from $N=77$ to $N=67$. So in the triaxial-core model, the odd-parity levels can be considered as originating from an $\mathrm{h}_{11 / 2}$ neutron-hole coupled to a $\beta=+0.29$ and $\gamma=13.5^{\circ}$ deformed core when the Fermi surface is located between the $5 / 2^{-}$and $7 / 2^{-}$ orbitals of $h_{11 / 2}$ neutron shell. Such a location of the Fermi surface corresponds to 7 holes in the shell.

From the systematics, one deduces a smooth lowering of level energies (relative to the first 11/2state) towards the neutron deficient isotopes which clearly indicates an increase of the positive $\beta$ deformation. The $\gamma$ deformation varies in an opposite way and goes down to a low value in ${ }^{123} \mathrm{Ba}$. Everything occurs as if the characteristic properties of the triaxial rotors were progressively dimmed when going towards more neutron deficient nuclei. For example, it was impossible to find the second $15 / 2^{-}$and $19 / 2^{-}$levels in ${ }^{123} \mathrm{Ba}$ which very likely are pushed upwards and are surely weakly fed in the $\left({ }^{12} \mathrm{C}, 3 \mathrm{n}\right)$ reaction. The level sequence tends now to become similar to the one in the strongly deformed nuclei.

4.2 Comparisons BetweEN $N=67$ ISOTONES. It seems interesting to consider systematics as a function of the proton number $Z$ to look for properties of high-spin levels when going away from the $Z=50$ proton closed shell. Results actually available relative to negative-parity levels generated from the $h_{11 / 2}$ neutron shell are shown in figure 3 where the energies of the $11 / 2^{-}$state are all set to zero to facilitate the comparisons.

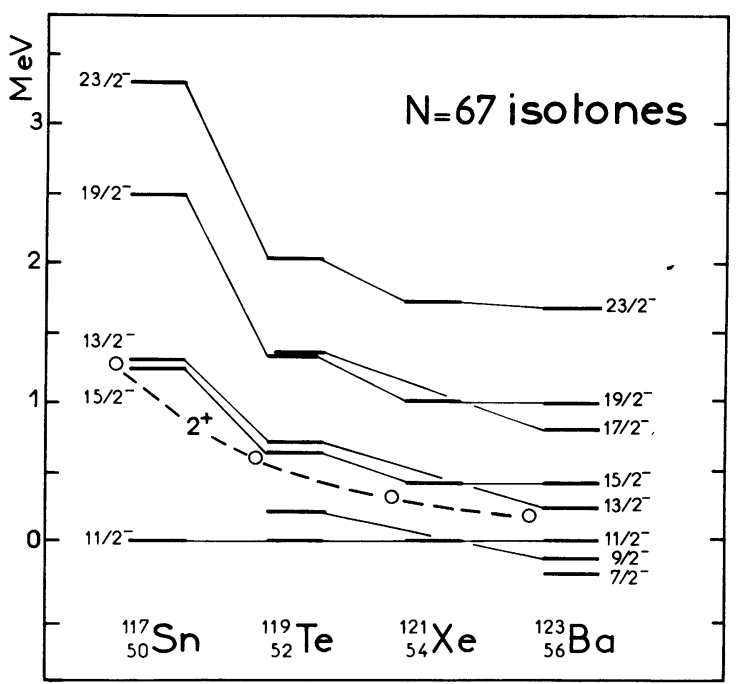

Fig. 3. - Systematics of odd-parity levels from the $h_{11 / 2}$ shell in $N=67$ isotones. The energies of the first $11 / 2^{-}$state are all set to zero. The open circles correspond to the $2^{+}$levels in the $N=66$ even-even cores. 
A $\Delta I=1$ band above this $11 / 2^{-}$state has been excited in ${ }^{117} \mathrm{Sn}$ [Ref. [18]] and ${ }^{119} \mathrm{Te}$ [Ref. [19]] through the ${ }^{116} \mathrm{Cd}(\alpha, 3 \mathrm{n})$ and ${ }^{117} \mathrm{Sn}(\alpha, 2 \mathrm{n})$ reactions, respectively. The case of ${ }^{121} \mathrm{Xe}$ which is inserted in the systematics requires some explanations. A cascade of E2 transitions has been found in the

$$
{ }^{110} \mathrm{Cd}\left({ }^{14} \mathrm{~N}, \mathrm{p} 2 \mathrm{n}\right){ }^{121} \mathrm{Xe}
$$

reaction and interpreted as a $\Delta I=2$ decoupled band built on a $\left(9 / 2^{-}\right)$state [20]. In a recent investigation [21], it is shown in contradiction with earlier data, that the $\Delta I=2$ cascade of strong stretched E2 transitions in the odd- $A^{123-133}$ Xe nuclei always lies on the first $11 / 2^{-}$state. Though the relative position of the lowest $9 / 2^{-}$and $11 / 2^{-}$levels in ${ }^{129} \mathrm{Xe}$ is unknown until now, we believe that the observed E2 sequence is built on the $11 / 2^{-}$level. So, the spacings between the $11 / 2^{-}, 15 / 2^{-}, 19 / 2^{-}, 23 / 2^{-}$and $27 / 2^{-}$levels in ${ }^{121} \mathrm{Xe}$ fit perfectly with the ones in heavier isotopes (see figure 5 in reference [21]).

A continuous decrease of the level energies clearly shows up in figure 3 when going from $\operatorname{Sn}(Z=50)$ to $\mathrm{Ba}(Z=56)$. However, one must observe that all the levels do not behave in the same way and it is interesting to compare them to the $2^{+} \rightarrow 0^{+}$transitions in the corresponding cores.

First, the $15 / 2^{-} \rightarrow 11 / 2^{-}$spacing in the odd-nuclei is roughly equal to the $2^{+} \rightarrow 0^{+}$transition of the core fore $Z=50$ and about twice in the barium case ( $Z=56$ ). Secondly, it appears from the $N=67$ syste- matics that the energy of the $13 / 2^{-} \rightarrow 11 / 2^{-}$transition in the odd- $A$ cases is close to that of the first $2^{+}$ excited state of the even-even $(A-1$ or $A+1)$ cores. The same features exist in $N=69,71$ and 73 isotones.

All these trends can be understood in a first approximation if one considers

i) ${ }^{117} \mathrm{Sn}$ as a vibrational nucleus where the $13 / 2^{-}$ and $15 / 2^{-}$states are members of the almost degenerated doublet produced by the coupling of an $h_{11 / 2}$ neutron-hole to the $2^{+}$core excitation.

ii) ${ }^{123} \mathrm{Ba}$ as a prolate-type triaxial nucleus with a large $\beta$ value $(+0.29)$ and a moderate $\gamma$ deformation $\left(\sim 13^{\circ}\right)$ as already mentionned in subsection 4.1.

iii) ${ }^{119} \mathrm{Te}$ and ${ }^{121} \mathrm{Xe}$ also as transitional nuclei which can be treated in the triaxial-rotor-plus-particle model by coupling an $h_{11 / 2}$ neutron-hole to the triaxial core [19], [21] or understood in a more general core-quasiparticle model [22].

In conclusion, a band structure of high-spin levels has been identified in ${ }^{123} \mathrm{Ba}$ through the ${ }^{1{ }^{14}} \mathrm{Sn}\left({ }^{12} \mathrm{C}, 3 \mathrm{n}\right)$ reaction. Its main features and comparisons with isotopes and isotones show that this neutron-deficient nucleus is situated in a region between the moderately deformed transitional nuclei and the strongly deformed rotational-type nuclei.

Acknowledgment. - One of us (N. Y.) wants to thank the Institut National de Physique Nucléaire et de Physique des Particules for supporting his stay at the Institut des Sciences Nucléaires de Grenoble.

\section{References}

[1] Grzon, J. and Gizon, A., Proc. of the 3rd Int. Conf. on Nuclei far from Stability, Cargese, May 1976, p. 401.

[2] Gizon, J., Gizon, A., Diamond, R. M. and Stephens, F. S., Nucl. Phys. A 290 (1977) 272.

[3] Gizon, J., Gizon, A., Diamond, R. M. and Stephens, F. S., J. Phys. G 4 (1978) L-171.

[4] Meyer-ter-Vehn, J., Nucl. Phys. A 249 (1975) 111 ; 141

[5] Gizon, J., Gizon, A. and Meyer-ter-Vehn, J., Nucl. Phys. A 277 (1977) 464.

[6] Stephens, F. S., Leigh, J. R. and Diamond, R. M., Nucl. Phys. A 170 (1971) 321.

[7] Arlt, R., Jasinski, A., Neubert, N. and Ortlepp, H. G., Acta Phys. Pol. B 6 (1975) 433.

[8] Conrad, J. and Repnow, R., Z. Phys. A 276 (1976) 403.

[9] Yoshikawa, N., Gizon, J. and Gizon, A., Proc. Int. Conf. on Nuclear Structure, Tokyo, Sept. 1977, p. 361.

[10] Garg, U., Sjoreen, T. P. and Fossan, D. B., Proc. Int. Conf. on Nuclear Structure, Tokyo, Sept. 1977, p. 360.

[11] Tickle, R. S., Gray, W. S. and Griffin, H. C., Z. Phys. A 284 (1978) 385.

[12] Stippler, R., Lode, D., Schrader, H. and MunNich, F., Z. Phys. A 242 (1971) 121.
[13] Spejewski, E. H., Hopke, P. K. and Loeser, F. W., Nucl. Phys. A 146 (1970) 182

[14] Begdolt, A. M., Chevallier, J., Merdinger, J. C., Bozek, E. and Stachura, Z., Proc. European Conf. on Nuclear Physics with Heavy Ions, Caen, Sept. 1976, p. 88.

[15] Gizon, A., Gizon, J. and Yoshikawa, N., Proc. Int. Symp. on High-spin States and Nuclear Structure, Dresden, Sept. 1977 , p. 17.

[16] Droste, Ch., Neubert, W., Chojnacki, S., Morek, T., Alexander, K. F. and Wilhelmi, Z., Nucl. Phys. A 192 595.

[17] Gizon, J. and Gizon, A., Z. Phys. A 285 (1978) 259.

[18] Hashimoto, O., Shida, Y., Ohya, S. and Sakai, M., Proc. Int. Conf. on Nuclear Structure, Tokyo, Sept. 1977, p. 344.

[19] Hagemann, U., Keller, H. J., Protochristow, Ch. and StaRY, F., Proc. Int. Conf. on Nuclear Structure, Tokyo, Sept. 1977 , p. 357

[20] Garg, U., Sjoreen, T. P., Chowdhury, P. and Fossan, D. B., Bull. Am. Phys. Soc. 22 (1977) 1026.

[21] Gizon, A. and Gizon, J., Z. Phys. A 289 (1978) 59.

[22] Donau, F. and Frauendorf, S., Proc. Int. Conf. on Nuclear Structure, Tokyo, Sept. 1977, p. 97. 